\title{
Clay flotation: Effect of TTAB cationic surfactant on foaming and stability of illite clay micro-
}

\section{aggregates foams}

\author{
AUTHORS NAMES \\ Julie C. M. Chapelain ${ }^{* 1,2}$, Sylvain Faure ${ }^{1}$, Davide Beneventi ${ }^{2,3,4}$ \\ 1CEA, DEN, DTCD, Marcoule,BP 17171,F-30207Bagnols-sur-Cèze,France,julie.chapelain@,cea.fr. \\ sylvain.faure@,cea.fr
}

2 Univ.Grenoble Alpes, LGP2, F-38000 Grenoble,France, Davide.Beneventi@pagora.grenoble-inp.fr

3 CNRS, LGP2, F-38000 Grenoble, France

4 Agefpi, LGP2, F-38000 Grenoble, France

\section{AUTHOR ADDRESS}

Corresponding author

Julie C. M. Chapelain, Tel: +33 6233703 45, Postal address: CEA Marcoule (Julie Chapelain, Bâtiment 56),

BP 17171, 30207 Bagnols-sur-Cèze, France, julie.chapelain@,cea.fr 
Illite

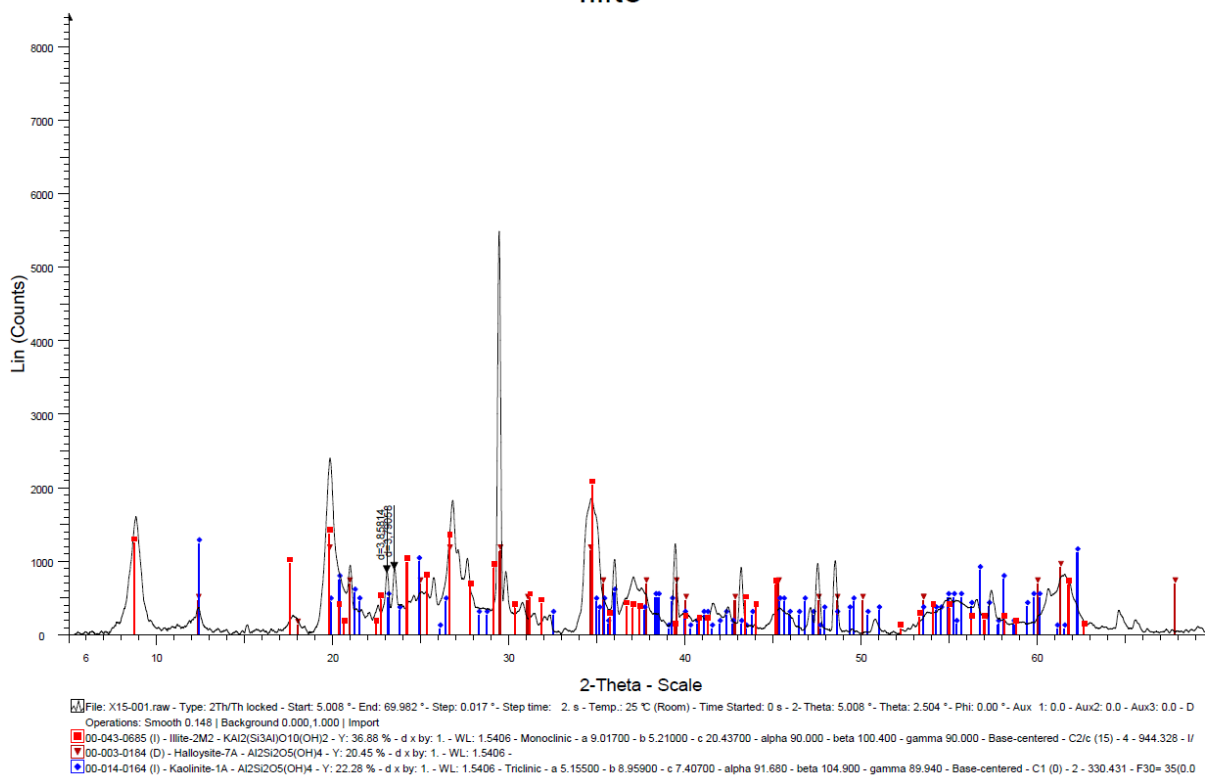

Fig. A: Illite clay diffractogram

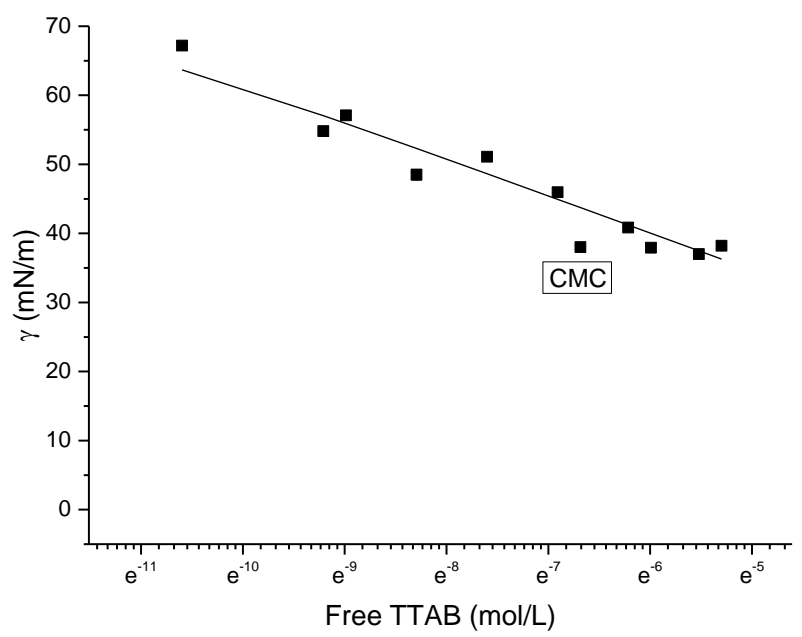

Fig. B: Evolution of surface tension $\gamma$ with free TTAB concentration (or added TTAB) in $270 \mathrm{mg} / \mathrm{L} \mathrm{CaCl}$ Milli $Q$ water in absence of illite clay; squares: experimental points - error bars are combined with data points; continuous line: Langmuir-Szyszkowski fitting points $\left(\Gamma_{\infty}=2.21 \times 10^{-6} \mathrm{~mol} / \mathrm{m}^{2}\right.$ and $a_{L}=6.02 \times 10^{-6}$ $\left.\mathbf{m o l} / \mathrm{m}^{3}\right)$ 

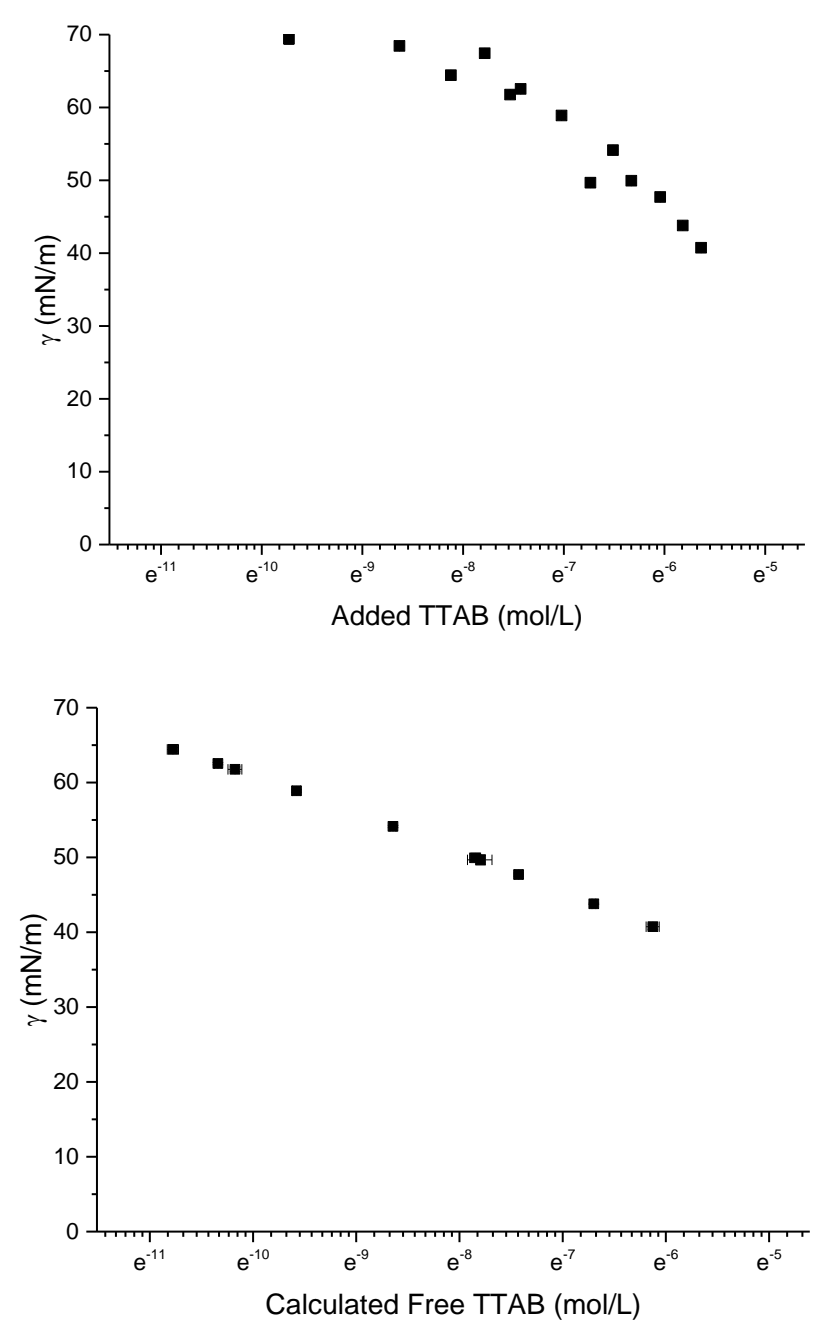

Fig. C: Evolution of surface tension $\gamma$ with added TTAB concentration (top) and calculated free TTAB (bottom) in $270 \mathrm{mg} / \mathrm{L} \mathrm{CaCl} \mathrm{Cilli}_{2} \mathrm{Q}$ water in presence of $5 \mathrm{~g} / \mathrm{L}$ of illite clay; Error bars on $\gamma$ and calculated free TTAB are combined with some of the data points

Details about the calculation of free and adsorbed TTAB error from figure $\mathrm{C}$ surface tension data:

The Langmuir-Szyszkowski fitting points $\left(\Gamma_{\infty}=2.21 \times 10^{-6} \mathrm{~mol} / \mathrm{m}^{2}\right.$ and $\left.\mathrm{a}_{\mathrm{L}}=6.02 \times 10^{-6} \mathrm{~mol} / \mathrm{m}^{3}\right)$ are determined by fitting as shown in figure B after having determined the surface tension of series of bare TTAB solutions at different concentrations. $\gamma_{0}$ is $72.5 \mathrm{mN} / \mathrm{m}$ (surface tension in absence of surfactant).

In presence of illite clay, calculated free TTAB concentration is calculated using the following expression:

Calculated Free TTAB $(\mathrm{mol} / \mathrm{L})=a_{L} \times e^{\frac{\gamma_{0} \times 10^{-3}-\gamma \times 10^{-3}}{R T \tau_{\infty}}}-1$

Adsorbed TTAB concentration is deduced from calculated free TTAB concentration:

Adsorbed TTAB $\left(\mathrm{g} / \mathrm{m}^{2}\right)=\frac{\text { Added TTAB-Calculated Free } T T A B}{\text { Concentration of illite clay } \times \text { illite clay specific area }}$

With: Added TTAB (mol/L): Concentration of TTAB added in the suspension before adsorption

Concentration of illite clay $(\mathrm{g} / \mathrm{L}): 5 \mathrm{~g} / \mathrm{L}$

Illite clay specific area: $95.5 \mathrm{~m}^{2} / \mathrm{g}$

The error on Calculated Free TTAB is calculated in the following way: 


$$
\begin{gathered}
\delta_{\text {Calculated Free } T T A B}=\frac{\partial}{\partial \gamma}\left(a_{L} \times e^{\frac{\gamma_{0} \times 10^{-3}-\gamma \times 10^{-3}}{R T \tau_{\infty}}}-1\right) \delta_{\gamma} \\
=a_{L}\left(\frac{-10^{-3}}{R T \tau_{\infty}} \times e^{\frac{\gamma_{0} \times 10^{-3}-\gamma \times 10^{-3}}{R T \tau_{\infty}}}\right) \delta_{\gamma}
\end{gathered}
$$

And $\delta_{\text {Adsorbed TTAB }}=\frac{\delta_{\text {Calculated Free } T \text { TAB }}}{\text { Concentration of illite clay } \times \text { illite clay specific area }}$
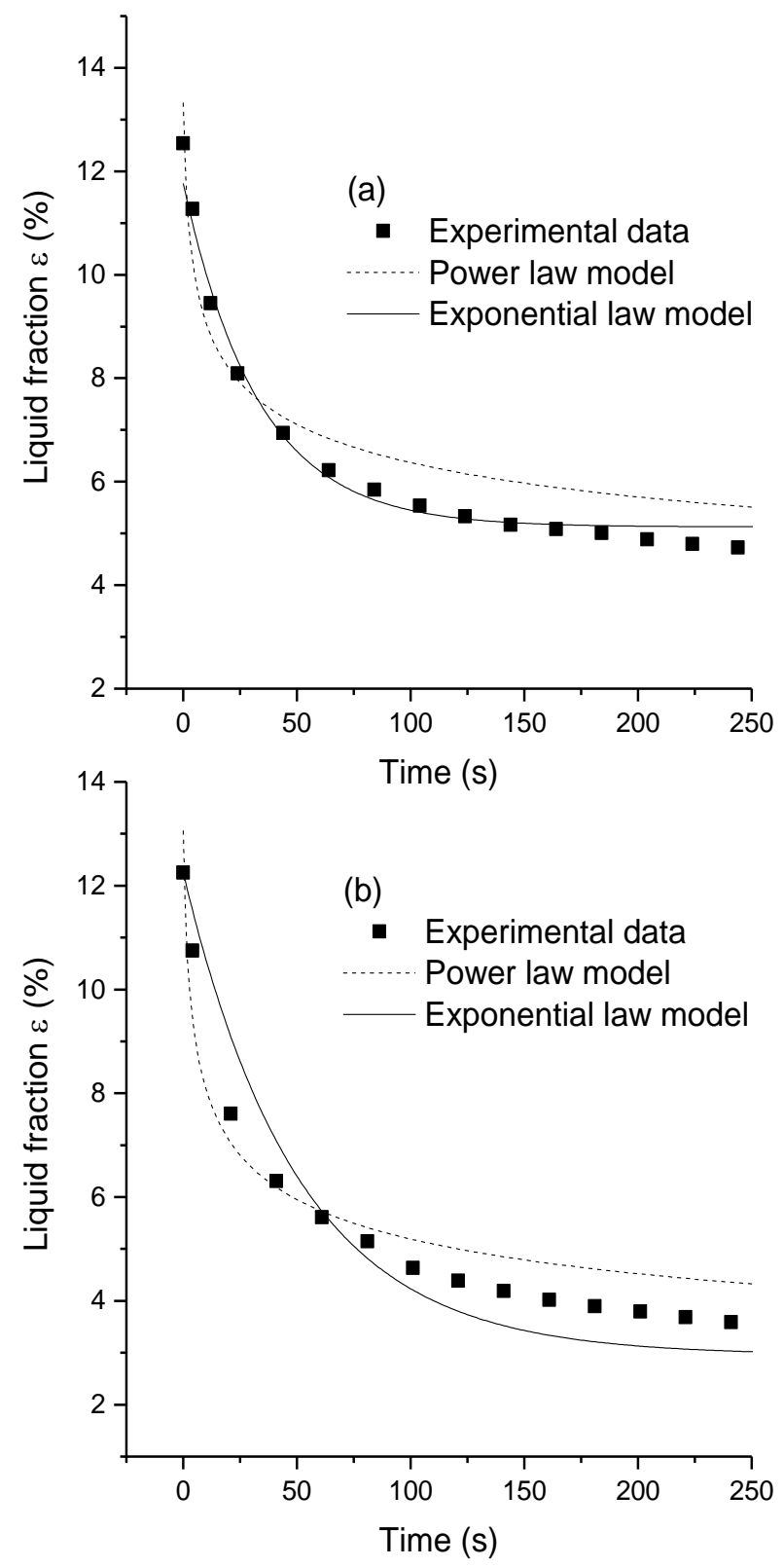


\begin{tabular}{|c|c|c|}
\cline { 2 - 3 } \multicolumn{1}{c|}{} & \multicolumn{2}{c|}{ Average error on liquid fraction (\%) } \\
\cline { 2 - 3 } & Power law model & Exponential law model \\
\hline $\begin{array}{c}\text { [illite] }=\mathbf{2 5 g} / \mathrm{L}, \\
\text { TTAB/illite ratio } \\
5.6 \%\end{array}$ & \pm 0.022 & \pm 0.020 \\
\hline $\begin{array}{c}\text { [illite]= 50g/L, } \\
\text { TTAB/illite ratio } \\
\text { 4\% }\end{array}$ & \pm 0.021 & \\
\hline
\end{tabular}

Fig. D: Comparison of power law and exponential law modeling for drainage: (a) [Illite]= 25 g/l TTAB/illite ratio $=5.6 \%$ (b) $[$ Illite $]=50 \mathrm{~g} / \mathrm{L}-\mathrm{TTAB} / \mathrm{illite}$ ratio $=4 \%$ (c) Table representing the average error between experimental and modelled data

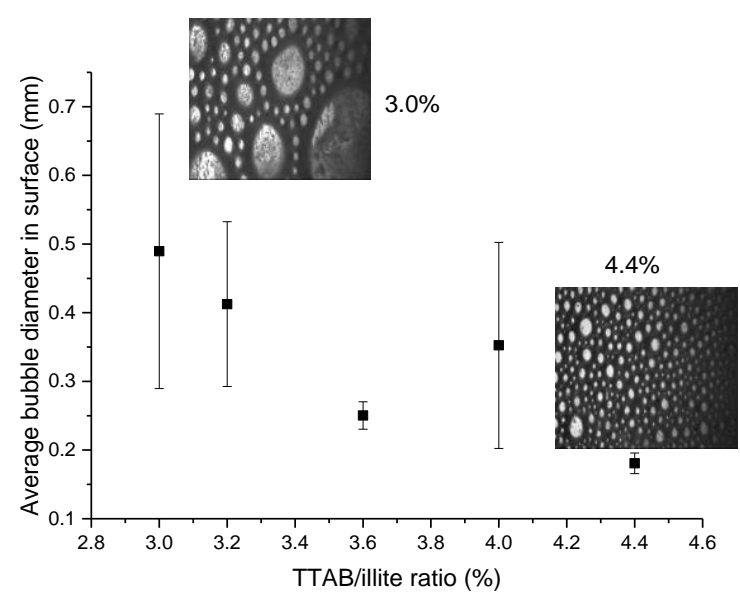

Fig. E: Evolution of average bubble diameter in surface with TTAB/illite ratio at $50 \mathrm{~g} / \mathrm{L}$ of illite clay. Pictures were taken $10 \mathrm{~s}$ after bubbling stop at about $1.5 \mathrm{~cm}$ from foam top of $30 \mathrm{~mL}$ of foam 